06

\title{
Влияние методов формирования полимерных композитных материалов с углеродными нанотрубками на механизмы электропроводности
}

\author{
(C) Ф.Ф. Комаров, ${ }^{1,2}$ И.Д. Парфимович, ${ }^{1}$ А.Г. Ткачев, ${ }^{3}$ А.В. Щегольков, ${ }^{3}$ А.В. Щегольков, ${ }^{3}$ \\ O.В. Мильчанин, ${ }^{1}$ В. Бондарев ${ }^{4}$
}

${ }^{1}$ Институт прикладных физических проблем им. А.Н. Севченко БГУ, 220045 Минск, Беларусь

${ }^{2}$ Научно-исследовательский технологический университет „МИСиС“, 119049 Москва, Россия

${ }^{3}$ Тамбовский государственный технический университет, 392000 Тамбов, Россия

4 Люблинский технический университет, 20-618 Люблин, Польша

e-mail: parfimovich@bsu.by

Поступило в Редакцию 9 июля 2020 г.

В окончательной редакции 1 сентября 2020 г.

Принято к публикации 18 сентября 2020 г.

\begin{abstract}
Проведены исследования влияния режимов формирования полимерных наноструктурированных композитов, наполненных углеродными нанотрубкам, на их электрофизические характеристики. Установлено влияние размерного эффекта многостенных углеродных нанотрубок, способа функционализации и метода ультразвуковой обработки на электропроводность композитных материалов в диапазоне частот $50 \mathrm{~Hz}-5 \mathrm{MHz}$ и диапазоне температур 15-375 К. Установлено наличие различных механизмов электрического транспорта в композитных материалах, оказывающих влияние на конечную величину электропроводности. Наилучшие результаты электрофизических параметров наблюдаются при сочетании нековалентной функционализации нанотрубок и сфокусированного ультразвукового воздействия. Метод позволяет добиться величины электропроводности композитных материалов $0.01 \mathrm{~S} / \mathrm{cm}$ в исследуемом диапазоне частот при концентрации наполнителя $0.5 \mathrm{wt} . \%$.
\end{abstract}

Ключевые слова: многостенные углеродные нанотрубки, эпоксидный полимер, композитный материал, электропроводимость.

DOI: $10.21883 / J T F .2021 .03 .50526 .222-20$

\section{Введение}

Электрический транспорт в неупорядоченных системaх, являющийся активной областью исследований, приобрел первостепенное значение с появлением функциональных органических материалов на основе полимеров с добавлением углеродных наноструктур так называемых композитов [1].

К настоящему времени существует огромное количество публикаций, посвященных изучению механизма появления электрической проводимости углеродных нанотрубок (УНТ) в различных полимерных системах. Однако изменение многих параметров, таких как тип УНТ, метод синтеза, функциональная обработка наноматериала, геометрические параметры, степень выравнивания и степень запутанности нанотрубок, а также тип полимера и метод дисперсии, затрудняет глубокое понимание механизмов электрической проводимости. Например, согласно анализу [2], порог электроперколяции волокнистой суспензии должен уменьшаться с увеличением аспектного отношения волокон, результаты работы [3] свидетельствуют о снижении порога перколяции с уве- личением длины УНТ, в то же время [4] наблюдали возрастающий порог перколяции с увеличением длины УНT.

Также авторами работы [1] при сравнении роли разных полимерных матриц отмечается более существенное различие в проводимости материалов, чем при сравнении влияния разных типов наполнителей. Это объясняется зависимостью процессов туннелирования носителей заряда через полимерные барьеры между УНТ. Таким образом, можно сделать заключение, что полимерные туннельные барьеры будут оказывать одно из доминирующих влияний на общий механизм проводимости композитов.

Критическим вопросом остается процесс диспергирования наноматериалов в матрице полимеров. Распределение первичных УНТ в эпоксидной матрице попрежнему остается проблемой из-за сильного взаимодействия между нанотрубками и проявлением эффекта самоагрегации [5]. Кроме природы матрицы и дисперсного наполнителя оказывают влияние также и режимы смешивания компонентов [6]. В работе [7] использована технология механического перемешивания. Одна- 
ко данный метод может не справиться с разделением массивов нанотрубок при низких концентрациях, либо при высоких концентрациях вызвать агрегацию УНТ. Это, в свою очередь, снизит вероятность возникновения электропроводящих путей в матрице полимера [8].

К другой технологии перемешивания дисперсного материала в полимерной матрице относится ультразвуковое диспергирование за счет кавитации [9]. Данный метод является одним из эффективных в вопросе создания композитов с однородным объемным распределением наноматериала. Однако если обработка ультразвуком слишком агрессивна или слишком длительна, УНТ могут быть серьезно повреждены, особенно при использовании ультразвукового зонда [10,11]. В свою очередь, дефекты структуры УНТ могут выступать в качестве рассеивающих носителей тока центров, что, в свою очередь, будет негативно сказываться на процессах электропереноса.

В совокупности с вышеупомянутыми методами диспергирования для обеспечения более однородного распределения УНТ в эпоксидной матрице используется технология функционализации [12].

Так как атомы углерода на стенках таких материалов как УНТ и графен химически стабильны из-за ароматической природы связи, углеродные наноматериалы (УНМ) являются инертными и могут взаимодействовать с матрицей полимера главным образом за счет ван-дер-ваальсового взаимодействия, которое неспособно обеспечить устойчивые связи через интерфейс УНМ/полимер.

Поэтому значительные усилия исследователей были направлены на разработку методов модификации свойств поверхности УНМ с целью обеспечения сопряжения поверхности данных материалов с полимерными матрицами. Существует несколько обзоров, которые описывают химические особенности функционализированных УНТ и механизмы реакции между УНТ и функциональными группами. Эти методы удобно разделить на ковалентную и нековалентную функционализации [12-15].

Прямая ковалентная функционализация боковой стенки связана с изменением гибридизации с $s p^{2}$ на $s p^{3}$ и одновременной потерей системы $p$-связей на слое графена. Этот процесс может быть осуществлен путем реакции с некоторыми молекулами с высокой химической активностью $[12,13,16]$.

Нековалентная функционализация нанотрубок обычно включает в себя ван-дер-ваальсовые, $\pi-\pi, \mathrm{CH}-\pi$ или электростатические взаимодействия между молекулами полимера и поверхностью УНТ [12,14]. Преимущество нековалентной функционализации состоит в том, что она в отличие от ковалентной не изменяет структуру УНТ и, следовательно, как электрические, так и механические свойства также должны оставаться неизменными. Однако эффективность силы между оберточными молекулами и поверхностью нанотрубки могут быть относительно слабыми, что может сказаться на эффектив- ности соединения полимерной матрицы с наполнителем. К тому же, остается неизвестной роль функциональных групп в механизмах электропроводности композитного материала.

Настоящая работа является развитием наших исследований по взаимодействию композитных материалов на основе эпоксидного полимера с УНТ с СВЧ-излучением Ка-диапазона [17]. В первую очередь, представленные результаты описывают зависимость электропроводности композитных материалов от размерных параметров многостенных УНТ (МУНТ), а также от способа их диспергирования.

Основное внимание в настоящей работе направлено на исследование влияния методов ультразвукового диспергирования, а также методов функционализации поверхности углеродных наноструктур на величину электропроводности композитов в широком частотном и температурном диапазонах, в связи с чем были использованы три методики диспергирования.

\section{1. Методика эксперимента}

В качестве объектов исследования выступали композитные материалы на основе эпоксидной полимерной матрицы ЭД-20 с добавлением различных по типу и концентрации МУНТ, производства компании „Нанотехцентр“ (г. Тамбов, Россия) (рис. 1).

На рис. $1, a, b$ представлены микрофотографии просвечивающей (ПЭМ) и сканирующей (СЭМ) электронной микроскопии УНТ с коммерческим названием „Таунит“. Данный класс нанотрубок имеют достаточно большой разброс по толщинам, средние их размеры можно оценить в диапазоне 40-70 nm. Форма трубок неровная регистрируются многочисленные места излома, изгиба, вплоть до острых углов. Концы трубок, как правило, имеют округлую форму. Трубки сильно переплетаются между собой, формируя сильно развитую и разупорядоченную сетку. Протяженность отдельных УНТ из-за скрученности и неоднородности исследуемого материала точно измерить не представляется возможным. По нашим оценкам длины УНТ попадают в диапазон от сотен нанометров до нескольких микрометров.

На рис. $1, c, d$ представлены ПЭМ и СЭМ микрофотографии для образцов УНТ с коммерческим названием „Таунит-М“. УНТ характеризуются меньшими толщинами в диапазоне 10-20 nm с преимущественным средним размером - 12-15 nm. Структура трубок сильно дефектна. Толщина трубок меняется на отдельных участках (не превышающих сотен нанометров) более чем в 2 раза. Многие УНТ имеют неправильную форму - присутствуют отростки, изгибы. В клубках трубок регистрируются и крупные частицы - кластеры с размерами до сотен нанометров. Переплетение нанотрубок в материале „Таунит-М“ гораздо более выражено, чем наблюдалось для материала „Таунит“. Однако в целом структура массива УНТ схожа с материалом „Таунит“. 

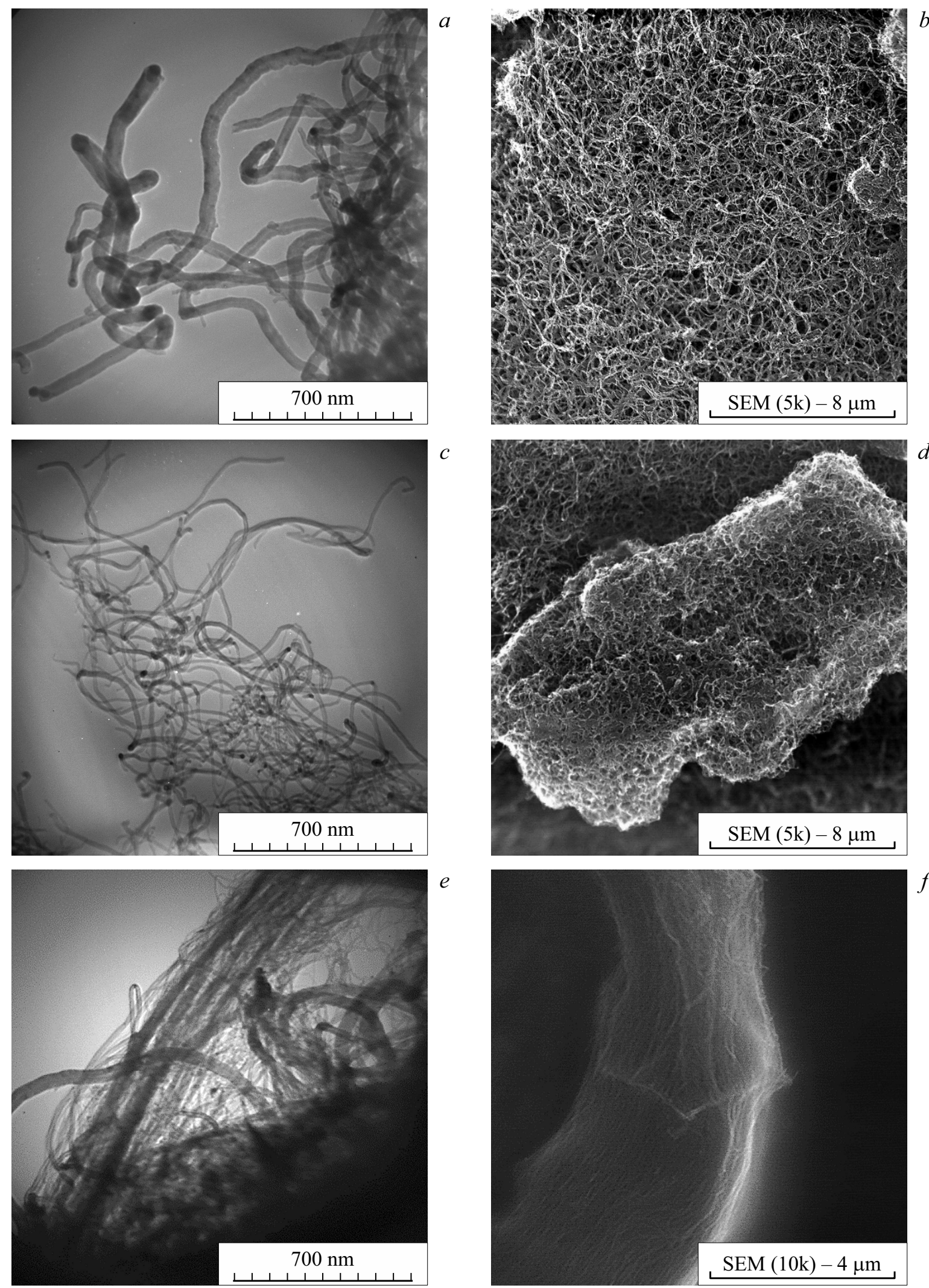

Рис. 1. ПЭМ $(a, c, e)$ и СЭМ $(b, d, f)$ микрофотографии образцов МУНТ: $a, b-$ „Таунит“, $c, d-$ „Таунит-М““, $e, f-$ „Таунит-МД““

На рис. 1, $e, f$ представлены микрофотографии УНТ „Таунит-МД“. Данный тип отличается от выше представ- ленных материалов упорядоченной структурой массива нанотрубок. 


\section{1. Метод совместного ультразвукового и гидромеханического воздействия}

Для получения композитных образцов исходной полимерной матрицы был выбран двухкомпонентный эпоксидный полимер марки ЭД-20. В качестве наполнителя выступали многостенные УНТ „Таунит“ и „Таунит-М““.

Процесс диспергирования УНМ в эпоксидном полимере проводился в ультразвуковой ванне при повышенной температуре $\left(65^{\circ} \mathrm{C}\right)$, с целью существенного снижения вязкости смолы, в течение $2-4 \mathrm{~h}$. Процесс включал „быстрое“ гидромеханическое перемешивание (до $2000 \mathrm{rpm}$ ) компонентов и одновременное ультразвуковое $(35 \mathrm{kHz})$ воздействие мощностью до $30 \mathrm{~W}$ [17]. Композитные образцы были изготовлены с различным содержанием МУНТ. Максимальные значения добавок МУНТ в матрицу ЭД-20 для „Таунита“ составило $16 \mathrm{wt. \%}$, а для „Таунит-М““ -8 wt.\%.

\section{2. Метод совместного ультразвукового и гидромеханического воздействия с предварительной функционализацией углеродных наноструктур}

Изготовление композитных материалов с наполнением в виде поверхностно функционализированных УНТ условно можно разделить на два этапа: 1) предварительная функциональная обработка поверхности углеродных наноструктур, 2) ввод и диспергирование наноструктур в матрице полимера.

Первый этап изготовления композитных материалов заключался в прививании к поверхности углеродных наноструктур ковалентных (стеариновая кислота), либо нековалентных (неионогенные поверхностно активные вещества) функциональных групп. В качестве наполнителя выступали МУНТ „Таунит-М““.

Подготовка углеродных наноструктур, подвергнутых ковалентной функционализации, включала следующие операции: 1) УНТ и стеариновую кислоту смешивали в массовом соотношении $1: 2 ; 2)$ обработка ультразвуковой ванной в этаноле при частоте $35 \mathrm{kHz}$ и мощности $30 \mathrm{~W}$ в течение $1 \mathrm{~h} ; 3)$ механическое перемешивание раствора при температуре $70^{\circ} \mathrm{C}$ в течение $1 \mathrm{~h}$; 4) выпаривание избытка кислоты из нанотрубок в сушильном шкафу в течение $24 \mathrm{~h}$ при температуре $100^{\circ} \mathrm{C}$; $5)$ промывку нанотрубок деионизированной водой с последующей сушкой в течение $24 \mathrm{~h}$.

Подготовка углеродных наноструктур, подвергнутых нековалентной функционализации, заключалась в формировании $100 \mathrm{mM}$-раствора неионогенных ПАВ в ацетоне, ультразвуковом диспергировании в УЗ-ванне наноструктур в растворе в течение $30 \mathrm{~min}$ на частоте $35 \mathrm{kHz}$ и мощности $30 \mathrm{~W}$, выпаривании избытка ПАВ в сушильном шкафу в течение $24 \mathrm{~h}$ при температуре $65^{\circ} \mathrm{C}$.

Второй этап процесса полностью совпадает с методикой изготовления нефункционализированных наноматериалов, описанной выше.

\section{3. Метод сфокусированного ультразвукового воздействия с предварительной нековалентной функционализацией углеродных наноструктур}

Для диспергирования в матрице полимера небольших концентраций УНМ, находящегося в связанном, сплетенном состоянии, необходимо использовать специальные методы для улучшения степени гомогенизации распределения добавок в объеме композитов. К таким методам относятся: использование поверхностно-активных веществ при диспергировании, а также ультразвуковое диспергирование при повышенных амплитудных и мощностных параметрах.

Данный метод включал этапы: 1) предварительную функциональную обработку поверхности углеродных наноструктур по описанной выше методике для ПАВ; 2) диспергирование эмульсии в течение 15 min при температуре, не превышающей $60^{\circ} \mathrm{C}$, при помощи ультразвукового сонотрода с плавным повышением мощности до $80 \mathrm{~W}$.

Для определения электропроводящих характеристик композитного материала использовалась измерительная установка для частотной диэлектрической спектроскопии нанокомпозитов и полупроводников, использующая метод измерений на переменном токе. Измерения проводились в диапазоне частот $50 \mathrm{~Hz}-5 \mathrm{MHz}$ и диапазоне температур $15-375 \mathrm{~K}$. Исследуемые образцы композитов вырезались в форме параллелепипеда с размерами в $10 \times 5 \times 1.5 \mathrm{~mm}$, что связано со строго заданными размерами держателей образцов в установке. Более подробное описание установки можно найти в работе [18].

\section{2. Результаты и обсуждение}

На рис. 2 представлены результаты измерений при комнатной температуре частотной зависимости удельной проводимости композитов на основе полимера ЭД20 с добавками наноматериалов „Таунит“ и „Таунит-М“, сформированных с использованием совместного ультразвукового и гидромеханического воздействия (методика 1).

Как видно из графиков, для небольших концентраций МУНТ в композите наблюдается такая же зависимость проводимости от частоты, как и для исходного полимера - с ростом частоты измерений происходит заметный рост проводимости, что характерно для поляризованных диэлектриков. Для больших концентраций добавок эта зависимость менее выражена. В образце с 8 wt.\% материала „Таунит-М“ на частотах измерений до $10 \mathrm{kHz}$ значение проводимости имеет постоянное значение порядка $10^{-7} \mathrm{~S} / \mathrm{cm}$. Подобное поведение наблюдается и для композитного материала с $16 \mathrm{wt} . \%$ материала „Таунит“ - значение проводимости остается постоянным $\left(\sim 10^{-5} \mathrm{~S} / \mathrm{cm}\right)$ во всем измеряемом частотном диапазоне. 

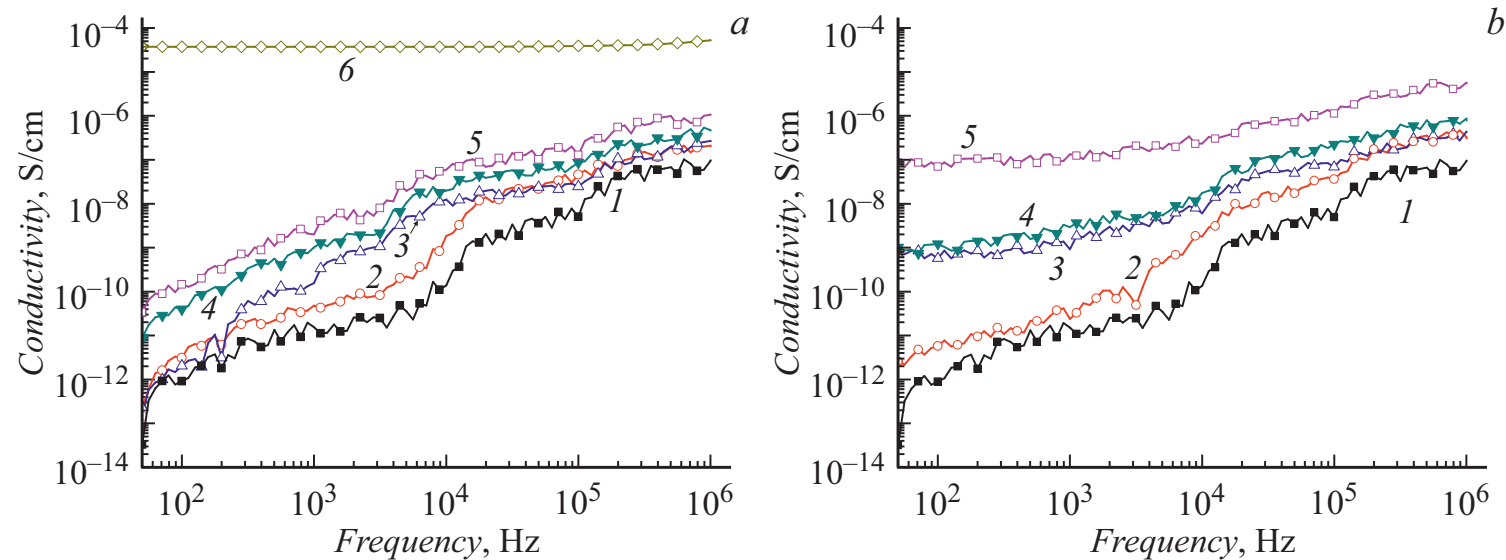

Рис. 2. Графики частотной зависимости проводимости для композитов с МУНТ „Таунит“ $(a)$ и „Таунит-М“ $(b): 1-$ исходный полимер, $2-1,3-2,4-4,5-8,6-16 \mathrm{wt} . \%$ УНТ.

Нетрудно заметить наличие так называемого „размерного эффекта“ [17]. Использование УНТ с меньшим диаметром („Таунит-М“), позволяет достичь больших значений удельной электропроводности композита в сравнении с более крупными нанотрубками с аналогичной массовой концентрацией. Что особенно заметно в низкочастотной области исследований: на частотах измерений до $100 \mathrm{~Hz}$ для одинаковых концентраций добавок с 1, 2, 4 и 8 wt.\% в композитах с „Таунитом-М“ проводимости примерно на 2 порядка величины больше, чем в композитах с материалом „Таунит“.

На рис. 3 представлена частотная зависимость электропроводности композитных образцов, изготовленных с применением совместного ультразвукового и гидромеханического воздействия с предварительной функционализацией УНТ (методика 2).

Как следует из представленных результатов измерения проводимости композитных материалов в зависимости от частоты, модификация поверхности углеродных наноструктур функциональными группами благоприятно сказывается на электрофизических свойствах всего композита. Так, при концентрации наполнителя „Таунит-М“ 2 wt.\% (кривые 2, 3) величина проводимости композитных материалов, полученных данным способом, сравнима с проводимостью композитов при концентрации наполнителя „Таунит“ в $16 \mathrm{wt} . \%$ и значительно превосходит композит с 8 wt.\% аналогичной добавкой „ТаунитM“, полученных без использования функциональных групп.

Для данного метода величина проводимости остается постоянной в диапазоне частот от $50 \mathrm{~Hz}$ до $100 \mathrm{kHz}$ и составляет $0.8 \cdot 10^{-4}$ и $0.7 \cdot 10^{-5} \mathrm{~S} / \mathrm{cm}$ для образцов, подвергнутых нековалентной и ковалентной функционализации соответственно. На частотах $100 \mathrm{kHz}-1 \mathrm{MHz}$ электропроводность демонстрирует линейный рост. При этом нанотрубки, функционализированные ПАВ, демонстрируют более резкое увеличение величины электропроводности - от $0.8 \cdot 10^{-4}$ до $0.7 \cdot 10^{-4} \mathrm{~S} / \mathrm{cm}$, против

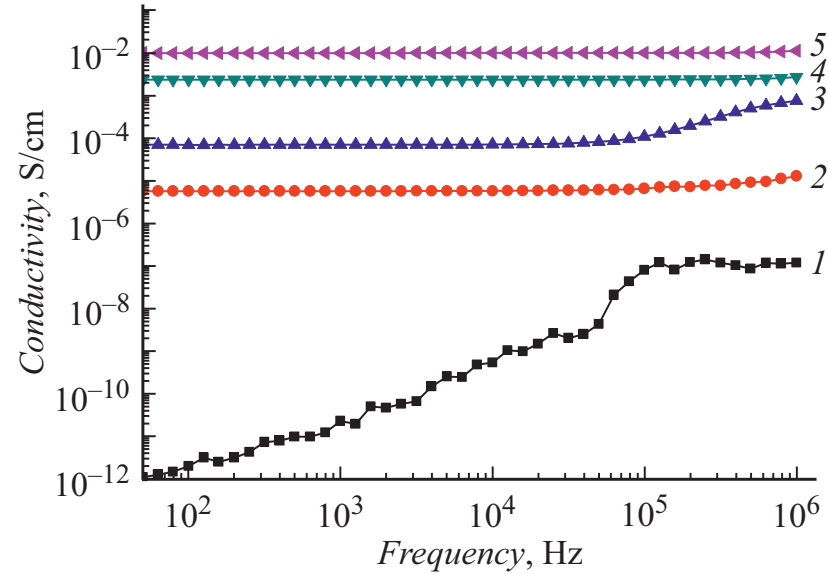

Рис. 3. Графики частотной зависимости электропроводности композитных материалов, изготовленных с применением различных методик диспергирования углеродных наноматериалов: 1 - исходный полимер, 2 - 2 wt.\% ковалентнофункционализированных нанотрубок „Таунит-М“, $3-2$ wt.\% нековалентно-функционализированных нанотрубок „ТаунитM“, 4 - 0.5 wt.\% нековалентно-функционализированных нанотрубок „Таунит-МД“, $5-0.5$ wt.\% нековалентнофункционализированных нанотрубок „Таунит-М“.

$0.7 \cdot 10^{-5}-1.2 \cdot 10^{-5} \mathrm{~S} / \mathrm{cm}$ для второго случая поверхностной обработки.

Меньшие значения удельной проводимости для композитных материалов с нанотрубками, подвергнутыми ковалентной обработке, могут объясняться тем, что кислотная модификация за счет ковалентных связей встраивает в структуру УНТ функциональные группы и, разрушая гексагональную графеновую решетку, образует дефекты на ее поверхности, выступающих в качестве рассеивающих заряд центров (кривая 2) [19]. В случае же нековалентной функционализации молекулы поверхностно активных веществ присоединяются к стенкам нанотрубок за счет электростатических сил межмолеку- 
Таблица 1. Результаты измерения электропроводности композитных материалов УНТ/эпоксидный полимер

\begin{tabular}{c|c|c|c}
\hline Наполнитель & $\begin{array}{c}\text { Метод } \\
\text { диспергирования }\end{array}$ & $\begin{array}{c}\text { Проводимость, } \\
\text { S/cm }\end{array}$ & Ссылка \\
\hline 1 wt.\% МУНТ & $\begin{array}{c}\text { Механическое } \\
\text { перемешивание } \\
\text { Механическое }\end{array}$ & 0.02 & {$[21]$} \\
15 wt.\% ОУНТ & $\begin{array}{c}\text { Перемешивание } \\
\text { У механическое } \\
\text { перемешивание } \\
\text { в растворе }\end{array}$ & 0.1 & {$[22]$} \\
1 wt.\% ОУНТ & УЗ & 0.0278 & {$[24]$} \\
УЗ & 0.0012 & {$[24]$}
\end{tabular}

лярного взаимодействия, не изменяя при этом структуру самих нанотрубок [14].

Использование метода сфокусированного ультразвукового воздействия с предварительной нековалентной функционализацией МУНТ (методика 3) в процессе формирования композитов позволяет добиться еще более высоких значений проводимости с постоянной величиной $\sim 0.01 \mathrm{~S} / \mathrm{cm}$ в исследуемом диапазоне частот при концентрациях наполнителя „Таунит-М“ в 0.5 wt.\% (кривая 5).

За счет сфокусированного ультразвукового воздействия происходит точечное воздействие на массив нанотрубок, что приводит к более эффективному их разделению. В свою очередь, использование поверхностно активных веществ не позволяет только что разделенным нанотрубкам за счет межмолекулярных сил притяжения повторно агломерироваться.

Для сравнения уровня полученного результата, в табл. 1 представлена информация о величинах электропроводности получаемых на системах композитных материалов УНТ/эпоксидный полимер $[1,20]$.

Таким образом, авторам работы удалось в некоторых случаях добиться сравнимых результатов электропроводности при меньших концентрациях наполнителя. Стоит отметить, что наибольший уровень электропроводности композитных материалов на основе диэлектрической матрицы с добавлением УНТ наблюдался для полиметилметакрилатовой матрицы с добавлением $10 \mathrm{wt} \%$ одностенных УНТ, допированных тионилхлоридом и составил порядка $100 \mathrm{~S} / \mathrm{cm}$ [25]. При этом максимально возможный уровень проводимости, демонстрируемый массивом чистых УНТ по данным публикаций, может достигать тысяч $\mathrm{S} / \mathrm{cm}$ как в случае с одностенными УНТ $(2500 \mathrm{~S} / \mathrm{cm})[25]$, так и МУНТ - $2380 \mathrm{~S} / \mathrm{cm}$ для разупорядоченных и $6200 \mathrm{~S} / \mathrm{cm}$ для упорядоченных нанотрубок [26].

Дальнейшее изучение электропроводящих характеристик сформированных композитных материалов строится на анализе температурной зависимости проводимости.
На рис. 4, $a, b$ представлена температурная зависимость проводимости композитных образцов с максимальными концентрациями добавок материалов „Таунит“ и „Таунит-М“, измеренные на частоте $10 \mathrm{kHz}$.

Как можно заметить, в композитных материалах с МУНТ присутствует, по крайней мере, 2 участка с различным характером температурной зависимости проводимости - низкотемпературный диапазон (от 50 до $10 \mathrm{~K}^{-1}$ ) и высокотемпературный диапазон (от 10 до $\left.2 \mathrm{~K}^{-1}\right)$.

Подобная зависимость проводимости от обратной температуры неоднократно встречалась в работах, посвященных изучению электрических свойств некристаллических полупроводниковых твердых тел [27-29]. Исходя из полупроводникового характера переноса заряда в МУНТ [30], композиты на их основе благодаря трансляции свойств трубок на матрицу полимера являются проводящими материалами с неупорядоченной структурой [20]. На энергетической диаграмме такого материала должны существовать хвосты локализованных состояний на краях валентной зоны и зоны проводимости, выходящие в запрещенную зону [27]. Кроме этого, у некристаллических полупроводников в запрещенной зоне могут возникать локализованные состояния, связанные с неупорядоченностью структуры материала, примесями, дефектами случайной сетки атомов, т.е. оборванными связями, вакансиями и т.д. - так называемые ловушки. При наличии таких дефектов плотность состояний оказывается немонотонной функцией энергии.

В соответствии с вышеуказанными особенностями в каждом температурном диапазоне доминируют различные механизмы проводимости, вносящие вклад в общую проводимость.

1. В области низких температур перенос носителей заряда по локализованным энергетическим состояниям осуществляется в основном за счет туннелирования через потенциальные барьеры.

2. В области высоких температур осуществляется механизм проводимости, связанный с переносом носителей зарядов в области запрещенной зоны за счет термически активированных прыжков между соседними локализованными энергетическими состояниями. Данный механизм проводимости получил название прыжковой проводимости с переменной длинной прыжка [27].

На рис. 4, $c-f$ представлена температурная зависимость проводимости композитных образцов, с предварительно функционализированной поверхностью МУНТ.

Для данных типов материалов наблюдается появление 3-го участка зависимости электропроводности от обратной температуры - в диапазоне от 4 до $2 \mathrm{~K}^{-1}$ происходит заметное снижение величины электропроводности. Данный эффект связан с проявлением механизма активированных диэлектрических потерь - в полях переменного тока, за счет поляризационных эффектов, связанные заряды диэлектрической матрицы композита образуют собственное поле, противоположное по 

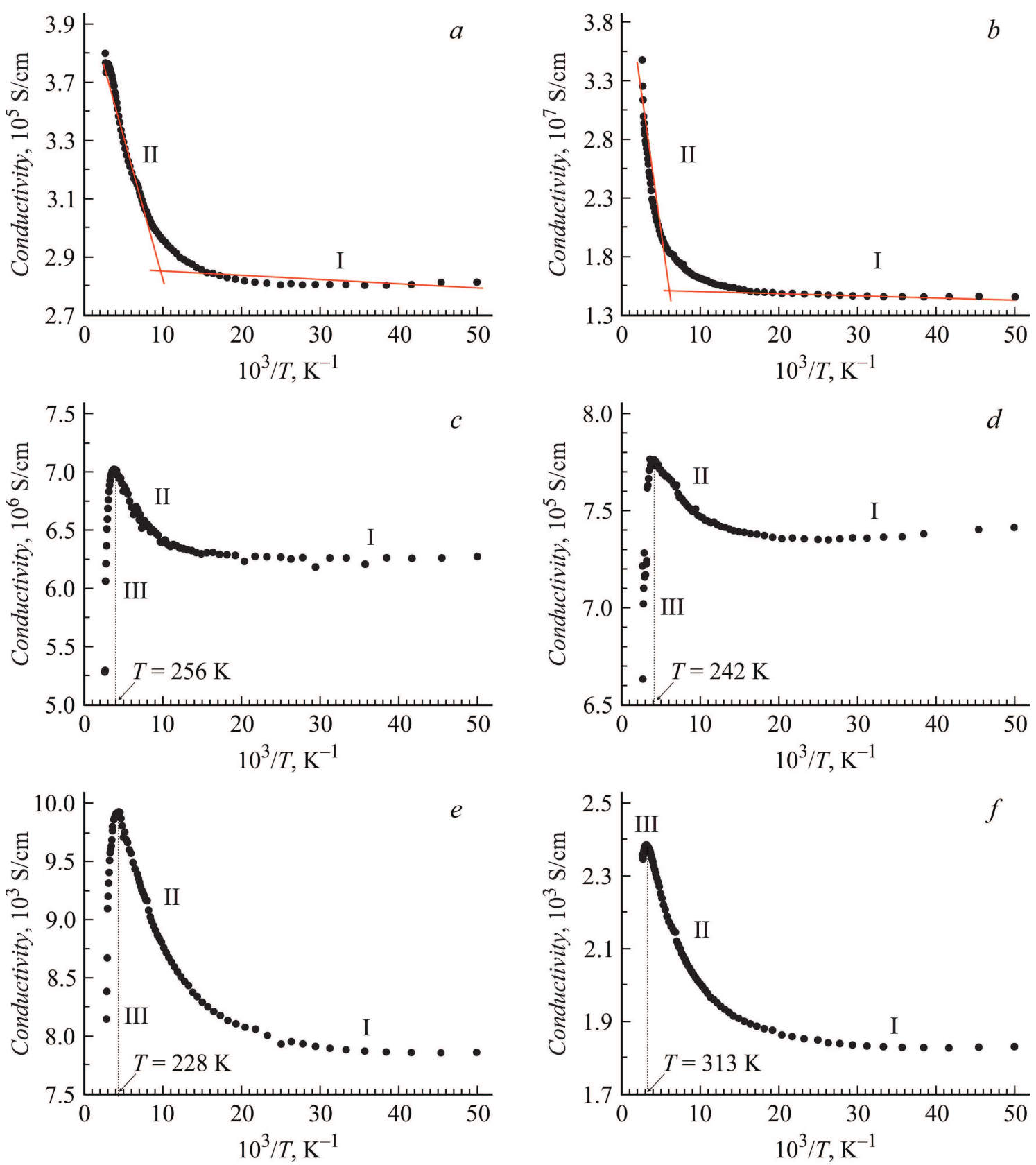

Рис. 4. Графики температурной зависимости образцов композитных материалов, сформированных с применение различных методик диспергирования: $a-16 \mathrm{wt} . \%$ „Таунит“ (методика 1), b-8wt.\% „Таунит-М“ (методика 1); с $2 \mathrm{wt} . \%$ „Таунит-М“ (методика 2), $d-2$ wt.\% „Таунит-М“ (методика 2); $e-0.5$ wt.\% „Таунит-М““ (методика 3$), f-0.5$ wt.\% „Таунит-МД“ (методика 3).

направлению внешнему полю, что приводит к потере переносимой энергии [31].

Любопытно отметить влияние типа добавки композитного материала на смещение точки снижения величины электропроводности. Так, для композитных материалов с добавлением МУНТ „Таунит-М“, разброс температурных значений начала проявления механизма потерь электропроводности колеблется в пределах $30 \mathrm{~K}$ $(228-256 \mathrm{~K})$.

В то же время в композитном материале с МУНТ „Таунит-МД“ активация механизма диэлектрических по- терь начинает проявляться при $313 \mathrm{~K}$. При этом наблюдается и меньшее снижение величины электропроводности. Однако стоит пояснить, что данный эффект наблюдается в образцах с улучшенными методами диспергирования. Для материалов, представленных на рис. 4, $a, b$, отсутствие участка, связанного с активированными диэлектрическими потерями, может быть вызвано тем, что данный механизм работает во всем температурном диапазоне и обусловливает столь низкие значения электропроводности при значительных концентрациях добавки. 

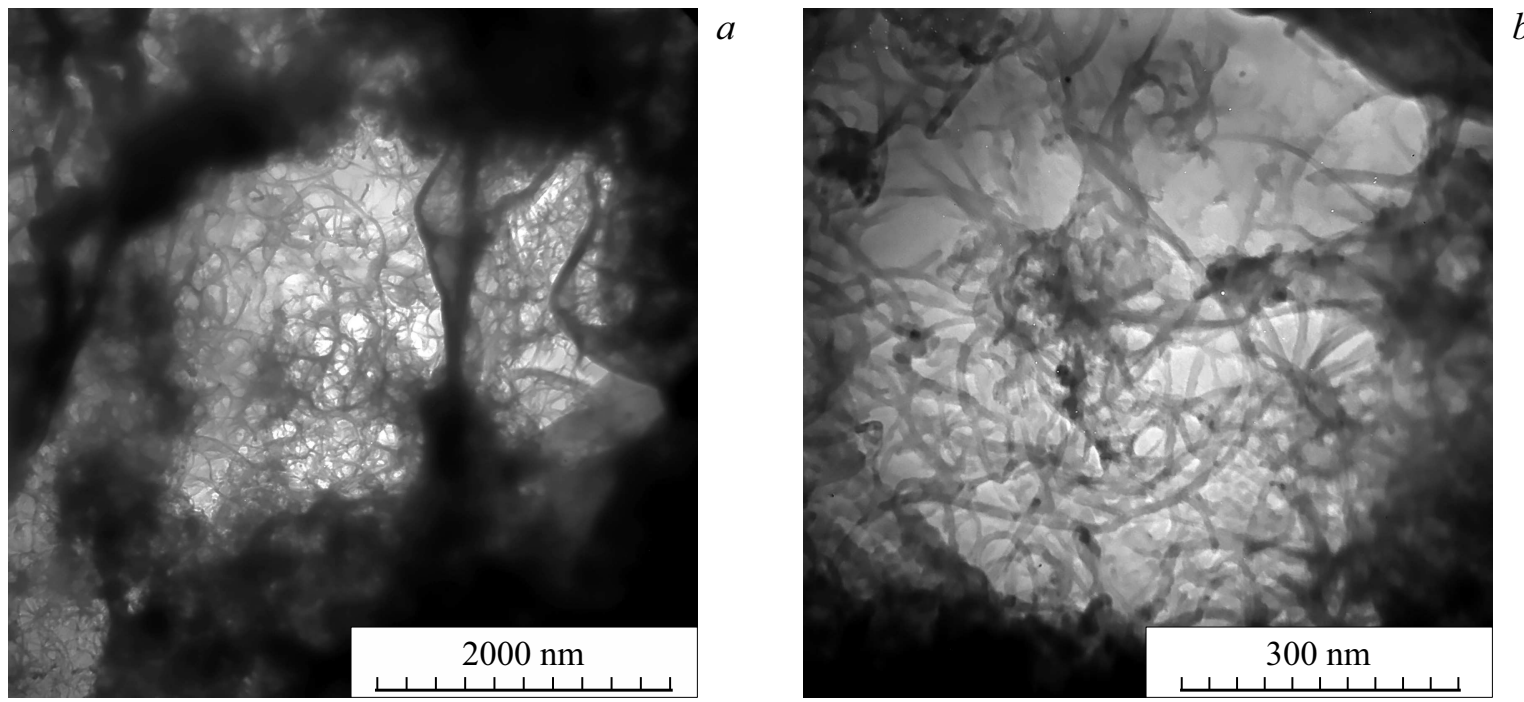

Рис. 5. ПЭМ микрофотографии образца композитного материала с 2 wt.\% МУНТ „Таунит-М“.

Таблица 2. Значения энергий термической активации композитных материалов с добавлением МУНТ

\begin{tabular}{|c|c|c|c|c|}
\hline \multirow{2}{*}{\multicolumn{2}{|c|}{$\begin{array}{c}\text { Концентрация и тип } \\
\text { добавки композита }\end{array}$}} & \multicolumn{3}{|c|}{$10 \mathrm{kHz}$} \\
\hline & & $\Delta E_{1}, \mathrm{eV}$ & $\Delta E_{2}, \mathrm{eV}$ & $\Delta E_{3}, \mathrm{eV}$ \\
\hline$* 1$ & 16 wt.\% „Таунит“ & 0.000118 & 0.00229 & \\
\hline$* 1$ & 8 wt.\% „Таунит-М““ & 0.000219 & 0.00934 & \\
\hline$* 2$ & $\begin{array}{c}2 \text { wt.\% „Таунит-М“ } \\
\text { (ПАВ) }\end{array}$ & 0.000026 & 0.00058 & 0.010 \\
\hline *2 2 & $\begin{array}{c}2 \text { wt.\% „Таунит-M““ } \\
\text { (стеарин) }\end{array}$ & 0.000041 & 0.00131 & 0.018 \\
\hline$* 3$ & 0.5 wt.\% „Таунит-М“ & 0.000134 & 0.0014 & 0.013 \\
\hline *3 & 0.5 wt.\% „Таунит-МД“ & 0.000172 & 0.0015 & 0.004 \\
\hline
\end{tabular}

Примечани е. * — методы изготовления композита.

Для каждого участка температурной зависимости электропроводности были рассчитаны значения термической активации (табл. 2). Анализ представленных в таблице результатов позволяет выделить ряд особенностей.

1. Наименьшим значением энергии активации обладает участок, соответствующий низкотемпературному диапазону - перенос заряда по локализованным состояниям за счет туннелирования носителей через потенциальные барьеры.

2. Улучшение методов диспергирования МУНТ в матрице композитного материала приводит к снижению энергии активации для 1-го и 2-го участков температурной зависимости электропроводности. За счет более эффективных методик диспергирования происходит равномерное распределение массивов нанотрубок в матрице полимера с образованием развитых объемных проводящих сетей (рис. 5). В результате становится возможным процесс переноса заряда в еще большем объеме компо- зита и придание ему проводящих свойств, сравнимых с проводящими свойствами самих МУНТ [30].

3. Наибольшими значениями энергии активации для композитных материалов, сформированных по методике 2 и 3, обладает участок, соответствующий термической активации диэлектрических потерь.

\section{Заключение}

Основываясь на представленных в работе результатах можно сделать заключение о критическом влиянии методов диспергирования и „размерного эффекта“ многостенных нанотрубок на электрофизические характеристики композитов на их основе.

Установлено, что для достижения наибольших значений удельной электропроводности материала в сочетании с сфокусированным ультразвуковым воздействием необходимо предварительно проводить нековалентную функционализацию поверхности УНТ. Данный метод позволяет добиться постоянного значения проводимости в $0.01 \mathrm{~S} / \mathrm{cm}$ в диапазоне частот от $50 \mathrm{~Hz}$ до $1 \mathrm{MHz}$ при концентрации наполнителя $0.5 \mathrm{wt} . \%$.

Сравнивая размерные характеристики МУНТ „Таунит-М“ и „Таунит“, следует отметить, что нанотрубки с меньшим диаметром позволяют достичь как минимум на 2 порядка больших значений величины электропроводности. В то же время МУНТ „Таунит-МД“, которые хоть и обладают упорядоченной структурой массива, не обеспечивают какие-либо выдающиеся электрофизические характеристики на фоне композитных материалов на основе „Таунит-М“. По-видимому, в процессах формирования электропроводящих путей в композитных материалах предпочтение отдается более запутанным системам.

Разработка эффективных методик диспергирования позволяет не только достичь высоких значений электропроводности при низких концентрациях наполнителя, 
но и более обстоятельно проанализировать механизмы электропереноса в композитном материале. Так, в настоящей работе получены сведения о наличии в композитных материалах, по крайней мере, трех механизмов, связанных с переносом носителей за счет туннелирования, прыжковой проводимости, и механизма активированных диэлектрических потерь.

\section{Финансирование работы}

Работа выполнена при поддержке гранта РФФИБРФФИ № Т18Р-249.

\section{Конфликт интересов}

Авторы заявляют, что у них нет конфликта интересов.

\section{Список литературы}

[1] W. Bauhofer, J.Z. Kovacs. J. Comp. Sci. Tech., 69 (10), 1486 (2009). https://doi.org/10.1016/j.compscitech.2008.06.018

[2] A. Celzard, E. McRae, C. Deleuze, M. Dufort, G. Furdin, J.F. Marâché. Phys. Rev. B., 54 (10), 6209 (1996). https://doi.org/10.1103/PhysRevB.53.6209

[3] J.B. Bai, A. Allaoui. Composites: Part A, 34 (8), 689 (2003). https://doi.org/10.1016/S1359-835X(03)00140-4

[4] C.A. Martin, J.K.W. Sandler, M.S.P. Shaffer, M.K. Schwarz, W. Bauhofer, K. Schulte, A.H. Windle. Compos. Sci. Tech., 64 (15), 2309 (2004). https://doi.org/10.1016/j.compscitech.2004.01.025

[5] K.W. Putz, O.C. Compton, M.J. Palmeri, S.T. Nguyen, L.C. Brinson. Adv. Funct. Mat., 20 (19), 3322 (2010). https://doi.org/10.1002/adfm.201000723

[6] Y.Y. Huang, E.M. Terentjev. Polymers, 4 (1), 275 (2012). https://doi.org/10.3390/polym4010275

[7] S. Kugler, K. Kowalczyk, T. Spychaj. J. P. Org. Coat., 111, 196 (2017). https://doi.org/10.1016/j.porgcoat.2017.05.017

[8] L. Jing, C.M. Peng, S.C. Wing, K.T. Chi, Z.T. Beng, J.K. Kim. Adv. Funct. Mater., 17, 3207 (2007). https://doi.org/10.1002/adfm.200700065

[9] L. Shaolei, L. Guangfen, T. Run. J. Mater. Sci., 51, 3513 (2016). https://doi.org/10.1007/s10853-015-9671-z

[10] K.L. Lu, R.M. Lago, Y.K. Chen, M.L.H. Green, P.J.F. Harris, S.C. Tsang. Carbon., 34 (6), 814 (1996). https://doi.org/10.1016/0008-6223(96)89470-X

[11] S. Badaire, P. Poulin, M. Maugey, C. Zakri. Langmuir, 20 (24), 10367 (2004). https://doi.org/10.1021/la049096r

[12] P.C. Ma, N.A. Siddiqui, G. Marom, J.K. Kim. Composites: Part A, 41 (10), 1345 (2010). https://doi.org/10.1016/j.compositesa.2010.07.003

[13] A. Setaro. J. Phys.: Condens. Matter., 29 (42), 423003(36) (2017). https://doi.org/10.1088/1361-648X/aa8248

[14] S.M. Fatemi, M. Foroutan. J. Nanostruct. Chem., 6, 29 (2016). https://doi.org/10.1007/s40097-015-0175-9

[15] Д.А. Шибаев, В.Ю. Орлов, Д.А. Базлов, В.Е. Ваганов. Химия и химическая технол., 54 (7), 38 (2011).

[16] А.В. Крестинин, А.П. Харитонов. Высокомол. соед., 60 (4), 340 (2108).
[17] F.F. Komarov, O.V. Milchanin, I.D. Parfimovich, M.V. Grinchenko, I.N. Parkhomenko, A.G. Tkachev, D.S. Bychenok. J. Appl. Spectr., 84 (4), 596 (2017). https://doi.org/10.1007/s10812-017-0516-1

[18] T.N. Koltunowicz. J. Appl. Spectr., 82 (4), 623 (2015). https://doi.org/10.1007/s10812-015-0158-0

[19] Z. Spitalsky, D. Tasis, K. Papagelis, C. Galiotis. J. Prog. Polum. Sci., 35, 357 (2010). https://doi.org/10.1016/j.progpolymsci.2009.09.003

[20] А.В. Елецкий, А.А. Книжник, Б.В. Потапкин, Х.М. Кенни. УФН, 185 (3), 225 (2015). [A.V. Eletskii, A.A. Knizhnik, B.V. Potapkin, J.M. Kenny. UFN, 185 (3), 225 (2015).] https://doi.org/10.3367/UFNr.0185.201503a.0225

[21] J.K.W. Sandler, J.E. Kirk, I.A. Kinloch, M.S.P. Shaffer, A.H. Windle. Polymer, 44 (19), 5893 (2003). https://doi.org/10.1016/S0032-3861(03)00539-1

[22] J.B. Bai, A. Allaoui. Composites: Part A, 34 (8), 689 (2003). https://doi.org/10.1016/S1359-835X(03)00140-4

[23] N. Li, Y. Huang, F. Du, X. He, X. Lin, H. Gao, Y. Ma, F. Li, Y. Chen, P.C. Eklund. Nano Lett., 6 (6), 1141, (2006). https://doi.org/10.1021/n10602589

[24] Е.А. Яковлев, Н.А. Яковлев, И.А. Ильиных, И.Н. Бурмистров, Н.В. Горшков. Вестник ТГУ. Химия. 3 (5), 15 (2017). DOI: $10.17223 / 24135542 / 5 / 2$

[25] V. Skakalova, U. Detlaff-Weglikowska, S. Roth. Synthetic Metals, 152 (1-3), 349 (2005). https://doi.org/10.1016/j.synthmet.2005.07.291

[26] I.W.P. Chen, R. Liang, H. Zhao, C. Zhang. Nanotechnology, 22 (48), 485708 (2011). https://doi.org/10.1088/0957-4484/22/48/485708

[27] N.F. Mott, E.A. Davis. Electronic processes in non-crystalline materials (Oxford: Clarendon Press, NY., 1979)

[28] K. Shimakawa. Philosophical Magazine Part B, 46 (2), 123 (1982). https://doi.org/10.1080/13642818208246429

[29] R.A. Street. Phys. Rev. B, 17 (10), 3984 (1978). https://doi.org/10.1103/PhysRevB.17.3984

[30] А.В. Елецкий. УФН, 179 (3), 225 (2009). https://doi.org/10.3367/UFNr.0179.200903a.0225

[31] A. Mansingh. Bull. Mater. Sci., (5), 325 (1980). https://doi.org/10.1007/BF02908579 